\title{
The Prevalence of HCV Infection and Risk Factors in a Hospital- Based Population Screening, a First Step to the Micro-Elimination of HCV Infection in Medical Institutions from Romania - Results of the HepC ALERT Study
}

\author{
Liana Gheorghe ${ }^{1,2}$, Speranta Iacob ${ }^{1,2}$, Irma Eva Csiki ${ }^{3}$, Laura Huiban ${ }^{4}$, Monica Cojocaru ${ }^{1,2}$, Camelia Cojocariu ${ }^{4}$, Roxana \\ Nemteanu ${ }^{4}$, Irina Girleanu ${ }^{4}$, Roxana Sirli ${ }^{5}$, Ana Maria Singeap ${ }^{4}$, Corina Pop ${ }^{6}$, Dan L. Dumitrascu ${ }^{7}$, Roxana Vadan $^{1}$, \\ Razvan Iacob $^{1,2}$, Mircea Diculescu ${ }^{1,2}$, Anca Trifan ${ }^{4}$, Ioan Sporea ${ }^{5}$, Cristian Gheorghe ${ }^{1,2}$
}

1) Digestive Diseases and

Liver Transplantation Center, Fundeni Clinical Institute, Bucharest;

2) Carol Davila University of Medicine and Pharmacy, Bucharest;

3) POCU Projects, Fundeni Clinical Institute, Bucharest;

4) Institute of

Gastroenterology and

Hepatology, Grigore T. Popa

University of Medicine and

Pharmacy, Iasi;

5) Department of

Gastroenterology and

Hepatology, Victor Babeș

University of Medicine and

Pharmacy, Timisoara;

6) Internal Medicine \&

Gastroenterology Department,

University Emergency

Hospital, Carol Davila

University of Medicine and

Pharmacy, Bucharest

7) $2^{\text {nd }}$ Department of Internal

Medicine, Iuliu Hatieganu

University of Medicine and

Pharmacy, Cluj-Napoca,

Romania

Address for correspondence: Cristian Gheorghe M.D.

PhD FASGE, Professor of

Gastroenterology

Carol Davila University of

Medicine and Pharmacy

Fundeni Clinical Institute

Bucharest, Romania

drcgheorghe@gmail.com

Received: 30.09.2020

Accepted: 13.11.2020

\section{ABSTRACT}

Background \& Aims: Elimination of hepatitis $\mathrm{C}$ worldwide is more feasible if micro-elimination screening strategies are adopted. We aimed to screen hepatitis $\mathrm{C}$ virus (HCV) in specific high-risk populations in certain sub-regions of Romania and link them to antiviral treatment.

Methods: A multicenter prospective study was conducted among the hospitalized or ambulatory adult patients from March 2019 to March 2020 in more than 20 medical institutions from 4 Romanian cities (Bucharest, Iasi, Timisoara, Cluj-Napoca). A rapid diagnostic test for HCV diagnosis was performed to all admitted patients and the positive ones were sent to gastroenterology departments for confirming the active infection, staging and treatment prescription.

Results: In total, 25,141 subjects signed the informed consent and were consequently enrolled into the study. The prevalence of anti-HCV antibodies was 1.39\% (95\%CI: 1.25-1.54) and increased with the number of risk factors presented by one subject. There was a positive association between the presence of anti-HCV antibodies and female gender $(\mathrm{p}<0.001)$, rural area of residence $(\mathrm{p}<0.001)$, advanced age $(\mathrm{p}<0.001)$, as well as a negative association with the education level $(\mathrm{p}<0.001)$.

Conclusions: In a hospital-based screening micro-elimination program in Romania, HCV prevalence was lower than previously reported. This is a first step towards a cost-effective screening in a well-defined group of persons at risk and provides sufficient capacity to deliver access to HCV treatment and linkage to care in Romania.

Key words: HCV - hepatitis C virus - micro-elimination - screening - link to care - public health.

Abbreviations: CI: confidence interval; DAA: direct-acting antiviral agent; $\mathrm{HCV}$ : hepatitis $\mathrm{C}$ virus; OR: odds ratio; SVR: sustained virological response.

\section{INTRODUCTION}

Chronic hepatitis $\mathrm{C}$ virus (HCV) infection represents nowadays a public health problem but also a socio-economic burden. The global estimated viremic HCV prevalence is around $1 \%$, corresponding to a number of 71 million persons with positive HCV RNA worldwide. The mean prevalence in Europe is $0.65 \%$, and Romania occupies the first place with $2.5 \%$ $\mathrm{HCV}$ prevalence, corresponding to 550,000 patients with positive viral loads $[1,2]$. Due to the asymptomatic character of the infection, most people $(>80 \%)$ are unaware of $\mathrm{HCV}$ positivity, are not tested, diagnosed and treated on time, in this way spreading the virus and discovering their condition when in advanced stages of liver disease [3].

An estimation of the number of people infected with HCV in the population is very important for the health policy of a given country. This allows planning of preventive and therapeutic interventions, and also determines the need for treatment of infected persons. The prevalence of anti-HCV antibodies in populations from Central and Eastern Europe varies between 0.27 and $3.5 \%$, the number of people infected with $\mathrm{HCV}$ in the general population being approximately 1.16 million [4].

The ambitious goal of eliminating viral hepatitis as a public health problem by 2030 will require major efforts to increase the screening rates and consequently the diagnosing rates, as well as to link the HCV positive patients to care in Romania, similar to other countries. 
With direct-acting antiviral agents (DAAs) therapy and its $\geq 95 \%$ cure rate, HCV elimination is clearly achievable. Increased treatment coverage and excellent sustained virological response (SVR) even in the later stages of liver disease have the greatest short-term impact on reducing morbidity and mortality, but treatment of any fibrosis stage (including F0-F1 fibrosis stage) is necessary to achieve reductions in total viremic infections and prevent ongoing transmission [5, 6]. Similar to other European countries, removing HCV treatment reimbursement restrictions in 2020 in Romania achieved great progress towards HCV elimination.

Micro-elimination, by targeting smaller and clearly delineated HCV risk groups, allows faster and better delivery of interventions. Development of possible micro-elimination scenarios breaking down national elimination goals into individual population segments enables policy makers to understand current disease landscapes on a hospital-based or regional level $[7,8]$. Thus, smaller scale policy initiatives targeting specific populations or localities are a tangible step towards achieving global elimination of HCV.

We aimed to screen $\mathrm{HCV}$ in specific high-risk populations in certain sub-regions of Romania and link them to antiviral treatment. This integrated project of testing-diagnosistreatment performed in over 20 medical institutions in Romania had as its objectives: micro-elimination of HCV at an institutional level among the patients that are admitted to medical units in Romania, prevention of advanced HCV liver disease, prevention of HCV transmission among the healthy population and updating the epidemiological data regarding $\mathrm{HCV}$ in Romania.

\section{METHODS}

A multicenter prospective study (HepC ALERT, HepC Awareness \& Test-Linkage to care-Epidemiological ResearchTreatment) was conducted among the hospitalized or ambulatory adult patients from March 2019 to March 2020 in more than 20 medical institutions from 4 Romanian cities (Bucharest, Iasi, Timisoara, Cluj-Napoca). Each center had included all consecutive patients addressed for routine monitoring or new patients for consultation, after signing the informed consent. A rapid diagnostic test for $\mathrm{HCV}$ diagnosis was performed to all admitted patients and the positive ones were sent to gastroenterology departments to confirm the active infection, staging and treatment prescription (linkageto-care). Demographic data on age, gender, area of residence, ethnicity, marital status, education, employment, and data on risk factors for $\mathrm{HCV}$ infection was collected through an epidemiologic questionnaire. All data were stored while performing the test in an anonymized database that could have been accessed online at any time.

The study was approved by the Institutional Ethics Committees and conformed to the ethical guidelines of the 1975 Declaration of Helsinki.

The prevalence of $\mathrm{HCV}$ positive patients was calculated with a 95\% confidence interval (CI). Qualitative or quantitative variables were analyzed using nonparametric tests, the Chisquare test, Kruskal-Wallis test or the Mann Whitney U test, as appropriate. Using logistic regression, odds ratio (OR) together with the corresponding 95\%CI were computed for the majority of investigated variables. All statistical tests were two-sided and a level of $\mathrm{p} \leq 0.05$ was used to indicate statistical significance. Statistical analysis was performed using the Stata/ SE 11 software.

\section{RESULTS}

\section{Prevalence of HCV infection}

In total, 25,141 subjects signed the informed consent and were consequently enrolled into the study. The prevalence of anti-HCV in the population that presented to the medical institutions in four big cities from Romania was $1.39 \%$ (95\%CI: 1.25-1.54). The distribution of patients, according to the 4 cities, was as follows: Bucharest $(12,875$ tested persons, $1.26 \%$ HCV prevalence); Cluj-Napoca (1,281 tested persons, 2.11\% HCV prevalence); Iasi (6,896 tested persons, $1.38 \%$ HCV prevalence); Timisoara (4,089 tested persons, $1.59 \%$ HCV prevalence) $(\mathrm{p}=0.054)$. The study population consisted of 15,802 females and 9,209 males. The HCV prevalence was similar among females and males $(1.47 \%$ vs. $1.27 \%, \mathrm{p}=0.199)$. The HCV prevalence for inhabitants of rural areas was $2.32 \%$ compared to $1.15 \%$ for subjects living in urban and metropolitan areas $(\mathrm{p}<0.001)$. The mean age of participants was $53.1 \pm 16.5$ years. The prevalence of HCV infection increased markedly with age $(\mathrm{p}<0.001)$ (Fig. 1). The Roma population had the highest HCV prevalence $2.91 \%$ compared to $1.39 \%$ in Romanians or $0.57 \%$ in Hungarians $(\mathrm{p}=0.178)$. Subjects with university education had a significantly lower prevalence of HCV (0.54\%) compared to subjects without school or just 4 years of primary school $(0.54 \%$ vs. $4.07 \%, \mathrm{p}<0.001)$. A higher $\mathrm{HCV}$ prevalence was observed among widowed subjects $(2.73 \%)$ in comparison to married or living together as a couple $(1.43 \%, \mathrm{p}<0.001)$. The prevalence of $\mathrm{HCV}$ infection was also associated with employment reflecting the social status (higher percentage in retired persons or housewives, 2.29\% and respectively $1.82 \%$ versus $0.65 \%$ in employees, $\mathrm{p}<0.001$ ).

Distribution of HCV prevalence according to the medical specialty where the patient presented for evaluation was: $2.61 \%$ otolaryngology, $1.74 \%$ hematology, $1.74 \%$ orthopedics, $1.73 \%$ gastroenterology, $1.63 \%$ nephrology, $1.56 \%$ internal medicine, $1.52 \%$ general surgery, $1.01 \%$ urology, $0.78 \%$ cardiology $(\mathrm{p}=0.006)$.

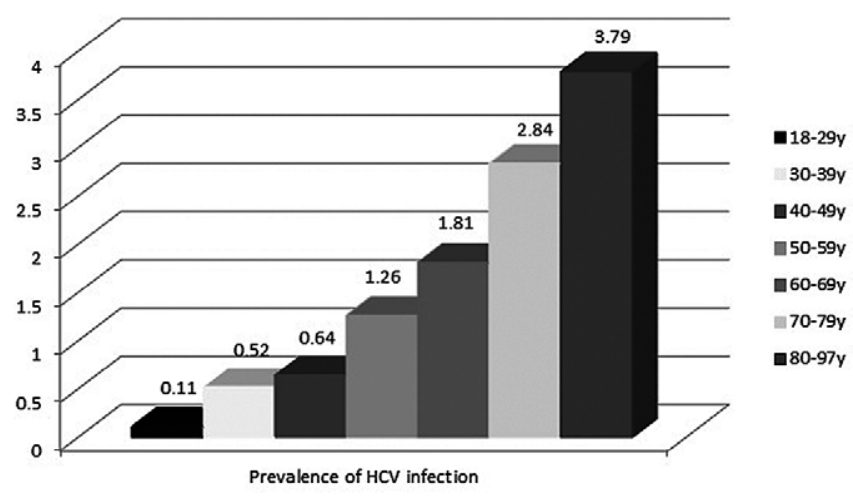

Fig. 1. Prevalence of HCV infection in different age groups. 
The highest HCV prevalence ( $>2 \%)$ according to counties from where the patients originated were as follows: Maramures (6.62\%), Tulcea (4.76\%), Arad (4.62\%), Dambovita (3.58\%), Calarasi $(2.72 \%)$, Bacau (2.71\%), Vrancea $(2.68 \%)$, Vaslui (2.6\%), Mehedinti (2.59\%), Neamt (2.42\%), Botosani (2.41\%), Giurgiu (2.32\%), Constanta (2.22\%), Suceava (2.1\%).

The prevalence of HCV positive antibodies in the study cohort according to the area of development is shown in Table I.

All HCV positive persons were scheduled for further evaluation in a tertiary gastroenterology/hepatology center in their city, in order to be linked to care. The patients that presented for staging of HCV infection and were detected with a positive $\mathrm{HCV}$ viral load from the total tested and detected HCV antibody positive were as follows: $80.2 \%$ in Bucharest, $66.6 \%$ in Cluj-Napoca, $86 \%$ in Iasi and $81.5 \%$ in Timisoara.

Table II shows the prevalence of HCV infection according to the risk factors identified by the addressed questionnaire. Only one risk factor (sexual contacts with multiple/unknown partners) showed no association with HCV seropositivity. The prevalence of anti-HCV antibodies increased with the number of risk factors present for one subject: if a patient had $\leq 1$ risk factors, the HCV prevalence was $0.49 \%$; if a patient had 2-3 risk factors, the HCV prevalence was $1.33 \%$, increasing to $2.56 \%$ in cases where a patient had $4-5$ risk factors or $6.48 \%$ in cases where a patient had $\geq 6$ risk factors $(\mathrm{p}<0.001)$. When taking into account the number of risk factors (4-17 risk factors), the regression analysis revealed a positive association between the presence of anti-HCV antibodies and female gender $(\mathrm{p}<0.001)$, rural area of residence $(\mathrm{p}<0.001)$ and advanced age $(\mathrm{p}<0.001)$, as well as a negative association with the education level $(\mathrm{p}<0.001)$. Table III depicts the OR resulted from multiple logistic regression for potential risk factors of HCV infection.

\section{DISCUSSION}

Hepatitis $\mathrm{C}$ is a systemic disease with hepatic and extrahepatic manifestations resulting in increased morbidity and mortality in HCV-infected patients compared to cured or uninfected individuals. Launched in 2016 by the World Health Organsation (WHO) and worldwide known, the Global Sectorial Strategy of Health for elimination of Viral Hepatitis as a threat for the health status of the population by 2030 has ambitious objectives: decrease of the incidence of the viral hepatitis by $90 \%$, diagnosis of $90 \%$ of the infected people, access to therapy to $80 \%$ of the diagnosed and eligible persons, reduction with $65 \%$ of the liver mortality through integrated actions of awareness, testing and access to treatment $[9,10]$. Also, the launch of the Elimination Manifesto on 17 February 2016 provided a starting point for action in order to make HCV and its elimination in Europe an explicit public health priority, to ensure that patients, civil society groups and other relevant stakeholders will be directly involved in developing and implementing HCV elimination strategies [11].

A key challenge to HCV elimination in Europe is the lack of reliable estimates of the burden of disease. Knowing the true burden of disease and the profile of those infected is necessary in order to design programmes and policies to scale-up prevention and treatment $[12,13]$.

Today, we are fighting with an important public health threat, COVID-19, which certainly needs special attention; however, we should not neglect medical care of other viruses and diseases such as HCV/HBV/HIV. Quarantine and social distancing for COVID-19 can affect diagnosis, treatment and harm reduction programs. Increasing people's awareness plays an important role in viral hepatitis elimination programs leading to more case finding $[14,15]$. Thus, we consider this paper a step forward in our public health achievements for viral hepatitis elimination until 2030 in Romania, in this current difficult situation of ongoing pandemic.

Success of this ambitious goal, at least in countries such as ours, is possible only by fragmentation in various strategies/ campaigns of micro-elimination (at national, institutional level, different target populations). However, this approach is used also in wealthy countries with very low prevalence such as Belgium or the Netherlands [16-18].

Table I. HCV prevalence in the screened subjects according to the area of development

\begin{tabular}{|c|c|c|c|c|}
\hline \multirow{2}{*}{$\mathrm{N}$} & \multirow{2}{*}{ Area of development } & \multirow{2}{*}{$\begin{array}{c}\text { Tested } \\
\text { subjects, } \mathrm{N}\end{array}$} & \multicolumn{2}{|c|}{ HCV Prevalence } \\
\hline & & & $\%$ & $95 \% \mathrm{CI}$ \\
\hline 1 & $\begin{array}{l}\text { North West (Bihor, Bistrița-Năsăud, Cluj, Maramureș, } \\
\text { Satu-Mare, Sălaj) }\end{array}$ & 1,124 & 1.96 & $1.29-2.96$ \\
\hline 2 & West (Arad, Caraș-Severin, Hunedoara, Timișs) & 3,887 & 1.44 & $1.11-1.87$ \\
\hline 3 & South West Oltenia (Dolj, Gorj, Mehedinți, Olt, Vâlcea) & 636 & 1.57 & $0.85-2.9$ \\
\hline 4 & $\begin{array}{l}\text { South Muntenia (Argeș, Călărași, Dâmbovița, Giurgiu, } \\
\text { Ialomița, Prahova, Teleorman) }\end{array}$ & 1,855 & 2.26 & $1.68-3.05$ \\
\hline 5 & $\begin{array}{l}\text { South Est (Brăila, Buzău, Constanța, Galați, Tulcea, } \\
\text { Vrancea) }\end{array}$ & 1,697 & 1.59 & $1.09-2.31$ \\
\hline 6 & North Est (Bacău, Botoșani, Iași, Neamț, Suceava, Vaslui) & 7,022 & 1.41 & $1.16-1.71$ \\
\hline 7 & Center (Alba, Brașov, Covasna, Harghita, Mureș, Sibiu) & 178 & 0.56 & $0.08-3.9$ \\
\hline \multirow[t]{2}{*}{8} & Bucharest - Ilfov & 8,742 & 1.05 & $0.86-1.29$ \\
\hline & Total screening cohort & 25,141 & 1.39 & $1.25-1.54$ \\
\hline & mparison of positive tests between regions)- $\mathrm{p}=0.003$ & & & \\
\hline
\end{tabular}


Table II. Prevalence of anti-HCV antibodies by different risk factors

\begin{tabular}{|c|c|c|c|c|}
\hline \multirow[t]{2}{*}{ Risk factors (answers from the questionnaires) } & \multirow{2}{*}{$\begin{array}{c}\text { Tested patients, } \\
\text { N }\end{array}$} & \multicolumn{2}{|c|}{$\mathrm{HCV}$ prevalence } & \multirow[t]{2}{*}{$\mathrm{p}\left(\mathrm{Chi}^{2}\right)$} \\
\hline & & $\%$ & $95 \% \mathrm{CI}$ & \\
\hline \multicolumn{5}{|l|}{ Previous known HBV/HDV } \\
\hline No & 24,391 & 1.35 & $1.22-1.51$ & 0.007 \\
\hline Yes & 750 & 2.53 & $1.62-3.94$ & \\
\hline \multicolumn{5}{|l|}{ Known HCV (+) family members } \\
\hline No & 23,983 & 1.28 & $1.15-1.43$ & $<0.001$ \\
\hline Yes & 1,158 & 3.63 & $2.69-4.87$ & \\
\hline \multicolumn{5}{|l|}{ Known HBV/HDV (+) family members } \\
\hline No & 23,911 & 1.35 & $1.21-1.5$ & 0.013 \\
\hline Yes & 1,230 & 2.2 & $1.51-3.18$ & \\
\hline \multicolumn{5}{|l|}{ Deceased relatives with LC/HCC } \\
\hline No & 22,351 & 1.34 & $1.2-1.5$ & 0.053 \\
\hline Yes & 2,790 & 1.79 & $1.36-2.36$ & \\
\hline \multicolumn{5}{|l|}{ Professional exposure to blood products } \\
\hline No & 20,413 & 1.63 & $1.46-1.81$ & $<0.001$ \\
\hline Yes & 4,728 & 0.36 & $0.22-0.58$ & \\
\hline \multicolumn{5}{|l|}{ Blood transfusions before 1992} \\
\hline No & 23,915 & 1.08 & $0.96-1.22$ & $<0.001$ \\
\hline Yes & 1,226 & 7.34 & $6.01-8.94$ & \\
\hline \multicolumn{5}{|l|}{ Abortion before 1990} \\
\hline No & 20,629 & 1.11 & $0.98-1.27$ & $<0.001$ \\
\hline Yes & 4,512 & 2.64 & $2.21-3.15$ & \\
\hline \multicolumn{5}{|l|}{ Multiple surgeries } \\
\hline No & 19,025 & 1.12 & $0.98-1.28$ & $<0.001$ \\
\hline Yes & 6,116 & 2.22 & $1.88-2.62$ & \\
\hline \multicolumn{5}{|l|}{ Multiple hospitalizations } \\
\hline No & 17,817 & 0.98 & $0.84-1.13$ & $<0.001$ \\
\hline Yes & 7,324 & 2.39 & $2.06-2.77$ & \\
\hline \multicolumn{5}{|l|}{ Multiple stomatological interventions } \\
\hline No & 11,703 & 0.97 & $0.81-1.17$ & $<0.001$ \\
\hline Yes & 13,438 & 1.75 & $1.54-1.98$ & \\
\hline \multicolumn{5}{|l|}{ Hemodialysis } \\
\hline No & 25,005 & 1.37 & $1.23-1.52$ & 0.003 \\
\hline Yes & 136 & 4.41 & $1.99-9.5$ & \\
\hline \multicolumn{5}{|c|}{ Car/ Work accidents requiring prolonged hospitalization } \\
\hline No & 24,064 & 1.35 & $1.22-1.51$ & 0.032 \\
\hline Yes & 1,077 & 2.14 & $1.42-3.19$ & \\
\hline \multicolumn{5}{|l|}{ Intravenous drugs } \\
\hline No & 25,085 & 1.36 & $1.22-1.51$ & $<0.001$ \\
\hline Yes & 56 & 16.07 & $8.53-28.23$ & \\
\hline \multicolumn{5}{|l|}{ Sexual contacts with multiple/unknown partners } \\
\hline No & 23,465 & 1.37 & $1.23-1.52$ & 0.306 \\
\hline Yes & 1,676 & 1.67 & $1.16-2.41$ & \\
\hline \multicolumn{5}{|l|}{ Sharing personal hygiene objects } \\
\hline No & 19,693 & 1.26 & $1.12-1.43$ & 0.001 \\
\hline Yes & 5,448 & 1.84 & $1.51-2.23$ & \\
\hline \multicolumn{5}{|l|}{ Tatooing/piercing } \\
\hline No & 23,270 & 1.34 & $1.2-1.49$ & 0.014 \\
\hline Yes & 1,871 & 2.03 & $1.48-2.78$ & \\
\hline
\end{tabular}

HBV: hepatitis B virus; HCV: hepatitis C virus; HDV: hepatitis D virus; LC: liver cirrhosis; HCC: hepatocellular carcinoma. 
Table III. Association between chronic HCV infection and a risk factor identified in the questionnaire

\begin{tabular}{|c|c|c|c|}
\hline Risk factors & OR & $95 \% \mathrm{CI}$ & $\mathrm{p}$ (Z test) \\
\hline Previous known HBV/HDV & 0.73 & $0.4-1.33$ & 0.306 \\
\hline Known $\mathrm{HCV}(+)$ family members & 2.21 & $1.48-3.3$ & 0.0001 \\
\hline Known $\mathrm{HBV} / \mathrm{HDV}(+)$ family members & 1.3 & $0.8-2.12$ & 0.287 \\
\hline Deceased relatives with $\mathrm{LC} / \mathrm{HCC}$ & 0.94 & $0.66-1.34$ & 0.729 \\
\hline Professional exposure to blood products & 0.24 & $0.14-0.41$ & 0.0001 \\
\hline Blood transfusions before 1992 & 3.15 & $2.28-4.36$ & 0.0001 \\
\hline Abortion before 1990 & 1.38 & $1.05-1.8$ & 0.020 \\
\hline Multiple surgeries & 0.85 & $0.62-1.17$ & 0.330 \\
\hline Multiple hospitalizations & 1.37 & $1.01-1.87$ & 0.045 \\
\hline Multiple stomatological interventions & 1.14 & $0.88-1.48$ & 0.306 \\
\hline Hemodialysis & 0.3 & $0.09-1.05$ & 0.060 \\
\hline $\begin{array}{l}\text { Car/ Work accidents requiring prolonged } \\
\text { hospitalization }\end{array}$ & 0.71 & $0.42-1.21$ & 0.204 \\
\hline intravenous drugs & 3.7 & $1.19-11.55$ & 0.024 \\
\hline Sexual contacts with multiple/unknown partners & 0.92 & $0.57-1.47$ & 0.718 \\
\hline Sharing personal hygiene objects & 1.49 & $1.14-1.95$ & 0.004 \\
\hline Tatooing/piercing & 1.26 & $0.84-1.91$ & 0.265 \\
\hline
\end{tabular}

For abbreviations see Table II

This concept targets specific population subgroups : children (under the age of 15 years), HCV/HIV-coinfected persons, birth cohorts, haemodialysis patients, those diagnosed with haemophilia, men who have sex with men, migrants, people with advanced liver disease, people who inject drugs, prisoners, and transplant recipients $[7,15,19,20]$. In Romania, besides the already mentioned categories, we should include as target populations: people with intrafamilial transmission of $\mathrm{HCV}$, transfusions and abortions during the communist era, subjects with professional exposure to blood products and multiple hospitalizations. Also females, with advanced age, with a lower level of education and unemployed from rural areas were more susceptible to have HCV chronic infection. These results are in line with our previous research [21]. However, the overall prevalence was significantly lower $(1.39 \%$ vs $3.23 \%$ then previously reported). This trend indicates a cumulative risk of $\mathrm{HCV}$ infection over time, suggesting at the same time a cohort phenomenon with reduced transmission in recent years due to continuous improvement in healthcare conditions. The same aspects with decreased prevalence were noted in Italy [22, 23] and Spain [24].

A Polish study [25] reported the highest ratio of positive anti-HCV results in the group of young women aged $<35$ years with a positive history of at least one hospitalisation (5.5\%). This proportion was significantly higher compared to the group of patients with arterial hypertension (1.2\%) and patients with diabetes mellitus (1.06\%), also hospitalised at least once. In view of the obtained results it seems reasonable to look for new risk groups of $\mathrm{HCV}$ infection such as hospitalized persons in order to increase efficacy of screening and consecutively of micro-elimination.

The higher rural prevalence of HCV infection in Romania can be explained by the aging population in rural communities and a cohort effect, as well as by their hygiene conditions, lifestyle and mentalities which limit the access to medical facilities. Due to these real situations in Romania, our next screening project that will take place from 2020 to 2024 will target this kind of vulnerable population. The same results were reported in rural areas in Italy almost 20 years ago, with a HCV positivity prevalence rate of $22.4 / 100$, with increasing age trend, with positive predominance among females; data from this study showed the effects of the inappropriate use of medical or surgery practices on the population [26].

Other identified risk factors for HCV increased prevalence are noted also in Southern Italy: abuse of intravenous drugs among people $<60$ years old, a history of tattooing/piercing, a history of dental surgery or surgical interventions, at least one previous blood transfusion. However, the high number of migrants from Romania to Italy can account for the rather similar risk factors in areas with high HCV prevalence.

Removing HCV treatment reimbursement restrictions in many countries was a big step forward to HCV elimination. In Romania this happened only this year, but in other countries in Europe it occurred much earlier [6, 18, 27]. Another challenge is access to DAAs therapy, especially for people from rural areas. At present, it can be prescribed and initiated only by a gastroenterologist and is available only in certain big towns. If in the future, DAAs therapy could be prescribed by other health-care professionals and would be available in local pharmacies as well, treatment access would improve and patients would be able to receive their medication more conveniently. Consistent with our findings, HCV prevalence has increased with the rising burden of risk factors as shown also in the studies from France or Canada [28-32].

Elimination of hepatitis $\mathrm{C}$ worldwide appears plausible, with higher chances of success if micro-elimination strategies are adopted instead of macro-elimination strategies based on mass-screening. Our study was possible by the multidisciplinary 
team efforts that contributed to the testing of all admitted patients and subsequently the positive subjects were sent to treatment and care in Gastroenterology/Hepatology specialized tertiary centers. We propose this study as a possible approach to achieving HCV micro-elimination in hospitalized people. It brings up-to-date HCV prevalence data which will assist strategic micro-elimination planning that is currently lacking in Romania.

\section{CONCLUSIONS}

In this hospital-based screening micro-elimination program in Romania, HCV prevalence was lower (1.39\%) than previously reported.

In a national campaign aimed at improving case finding and increasing awareness of hepatitis $\mathrm{C}$, we demonstrated how targeted and locally adapted HCV testing and treating interventions may be successful in rapidly achieving microelimination in high risk patient populations. This is a first step towards a cost-effective screening in well-defined group of persons at risk and provides sufficient capacity to deliver access to HCV treatment and care in Romania, bringing our country closer to the achievement of the WHO objective.

\section{Conflicts of interest: None to declare.}

Authors' contributions: L.G., C.G. conceived and designed the study, and wrote the paper. S.I. performed the statistical analysis and wrote the paper. I.E.C. designed the study and performed the statistical analysis. S.I., L.H., M.C., C.C., R.N., I.G., R.S., A.M.S., C.P., D.D., R.I., R.V. tested the patients and collected the clinical data. C.P., M.D., D.D., A.T., I.S. conceived the study and revised the paper. All authors critically revised the manuscript, approved the final version to be published, and agree to be accountable for all aspects of the work.

\section{REFERENCES}

1. Han R, Zhou J, François C, Toumi M. Prevalence of hepatitis C infection among the general population and high-risk groups in the EU/EEA: a systematic review update. BMC Infect Dis 2019;19:655. doi:10.1186/ s12879-019-4284-9

2. European Union HCV Collaborators. Hepatitis C Virus Prevalence and Level of Intervention Required to Achieve the WHO Targets for Elimination in the European Union by 2030: A Modelling Study. Lancet Gastroenterol Hepatol 2017;2:325-336. doi:10.1016/S2468 1253(17)30045-6

3. Merkinaite S, Lazarus JV, Gore C. Addressing HCV infection in Europe: reported, estimated and undiagnosed cases. Cent Eur J Public Health 2008;16:106-110.

4. Madaliński K, Zakrzewska K, Kołakowska A, Godzik P. Epidemiology of HCV infection in Central and Eastern Europe. Prezgl Epidemiol 2015;69:459-464.

5. Chen DS, Hamoudi W, Mustapha B, et al. Strategies to manage hepatitis C virus infection disease burden-Volume 4. J Viral Hepat 2017;24 Suppl 2:44-63. doi:10.1111/jvh.12759

6. Marshall AD, Pawlotsky JM, Lazarus JV, Aghemo A, Dore GJ, Grebely J. Theremoval of DAA restrictions in Europe - one step closer to eliminating HCVas a major public health threat. J Hepatol 2018;69:1188-1196. doi:10.1016/j.jhep.2018.06.016

7. Lazarus JV, Wiktor S, Colombo M, Thursz M; EASL International Liver Foundation. Micro-elimination - A path to global elimination of hepatitis C. J Hepatol 2017;67:665-666. doi:10.1016/j. jhep.2017.06.033

8. Lazarus JV, Safreed-Harmon K' Thursz MR, et al. The MicroElimination Approach to Eliminating Hepatitis C: Strategic and Operational Considerations. Semin Liver Dis 2018;38:181-192. doi:10.1055/s-0038-1666841

9. World Health Organization (WHO). Monitoring and evaluation for viral hepatitis B and C: Recommended indicators and framework. Geneva: WHO; 2016. Available at: http://www.who.int/hepatitis/publications/ hep-b-c-monitoring-evaluation/en/

10. World Health Organization (WHO). Guidelines for thescreening, care and treatment of persons with chronic hepatitis $\mathrm{C}$ infection. Updated version. Geneva: WHO; Apr 2016. Available at: https://www.who.int/ hepatitis/publications/hepatitis-c-guidelines-2016/en/

11. Papatheodoridis GV, Hatzakis A, Cholongitas E, et al. Hepatitis C: The beginning of the end-key elements for successful European and national strategies to eliminate HCV in Europe. J Viral Hepat 2018;25 Suppl 1:6-17. doi:10.1111/jvh.12875

12. World Health Organization (WHO). Combating Hepatitis B and C to reach elimination by 2030. Geneva: WHO; May 2016; http://www.who. int/hepatitis/publications/hep-elimination-by-2030-brief/en/

13. Hahné SJM, Veldhuijzen IK, Wiessing L, Lim TA, Salminen M, van de Laar M. Infection with hepatitis B and C virus in Europe: a systematic review of prevalence and cost-effectiveness of screening. BMC Infect Dis 2013;13:181. doi:10.1186/1471-2334-13-181

14. Karimi-Sari H, Tajik M, Bayatpoor ME, Alavian SM. Increasing the awareness of the general population: an important step in elimination programs of viral hepatitis. Am J Gastroenterol 2017;112:393-395. doi:10.1038/ajg.2016.534

15. Hagan LM, Kasradze A, Salyer SJ, et al. Hepatitis C prevalence and risk factors in Georgia, 2015: setting a baseline for Elimination. BMC Public Health 2019; 19(Suppl 3):480. doi:10.1186/s12889-019-6784-3

16. Kracht PAM, Arends JE, van Erpecum KJ, et al. Strategies for achieving viral hepatitis C micro-elimination in the Netherlands. Hepato Med Policy 2018;3:12. doi:10.1186/s41124-018-0040-9

17. Soholm J, Holm DK, Mossner B, et al. Incidence, prevalence and risk factors forhepatitis C in Danish prisons. PLoS One 2019;14:e0220297. doi:10.1371/journal.pone.0220297

18. Busschots D, Toghanian S, Bielen R, et al. Eliminating viral hepatitis $C$ in Belgium: the micro-elimination approach. BMC Infect Dis 2020;20:181. doi:10.1186/s12879-020-4898-y

19. Lazarus JV, Pericàs JM, Colombo M, Ninburg M, Wiktor S, Thursz M. Viral hepatitis: “E” is for equitable elimination. J Hepatol 2018;69:762764. doi:10.1016/j.jhep.2018.06.018

20. Hollande C, Parlati L, Pol S. Micro-elimination of hepatitis C virus. Liver Int 2020;40 Suppl 1:67-71. doi:10.1111/liv.14363

21. Gheorghe L, Csiki IE, Iacob S, Gheorghe C, Smira G, Regep L. The prevalence and risk factors of hepatitis $\mathrm{C}$ virus infection in adult population in Romania: a nationwide survey 2006 - 2008. J Gastrointestin Liver Dis 2010;19:373-379.

22. Cozzolongo R, Osella AR, Elba S, et al; NUTRIHEP Collaborating Group. Epidemiology of HCV infection in the general population: a survey in a southern Italian town. Am J Gastroenterol 2009;104:27402746 
23. Guadagnino V, Stroffolini T, Rapicetta M, et al. Prevalence, risk factors, and genotype distribution of hepatitis $\mathrm{C}$ virus infection in the general population: a community-based survey in southern Italy. Hepatology 1997;26:1006-1011. doi:10.1002/hep.510260431

24. Rodríguez-Tajes S, Domínguez Á, Carrión JA, et al. Significant decrease in the prevalence of hepatitis $\mathrm{C}$ infection after the introduction of direct acting antivirals. J Gastroenterol Hepatol 2020;35:1570-1578. doi:10.1111/jgh.14984

25. Piekarska A, Berkan-Kawińska A. Prevalence of anti-HCV antibodies in the population of young women and general medicine patients. Przegl Epidemiol 2018;72:469-476. doi:10.32394/pe.72.4.22

26. Raffaele A, Valenti M, Iovenitti M, et al. High prevalence of HCV infection among the general population in a rural area of central Italy. Eur J Epidemiol 2001;17:41-46. doi:10.1023/a:1010932832190

27. Marshall AD, Cunningham EB, Nielsen S, et al. Restrictions for reimbursement of interferon-free direct-acting antiviral drugs for $\mathrm{HCV}$ infection in Europe. Lancet Gastroenterol Hepatol 2018;3:125-133. doi:10.1016/S2468-1253(17)30284-4
28. Buonomo AR, Scotto R, Pinchera B, et al. Epidemiology and risk factors for hepatitis $\mathrm{C}$ virus genotypes in a high prevalence region in Italy. New Microbiologica 2018;41:26-29.

29. Vaux S, Chevaliez S, Saboni L, et al. ANRS-Prevagay group. Prevalence of hepatitis $\mathrm{C}$ infection, screening and associated factors among men who have sex with men attending gay venues: a cross-sectional survey (PREVAGAY), France, 2015. BMC Infect Dis 2019;19:315. doi:10.1186/s12879-019-3945-Z

30. Reyes JC, Welch-Lazoritz M, Zayas-Martinez L, Khan B, Dombrowski K. Prevalence and Risk Factors associated with Homelessness among Drug Users in Puerto Rico. P R Health Sci J 2019;38:54-59.

31. Parmar P, Corsi DJ, Cooper C. Distribution of Hepatitis C Risk Factors and HCV Treatment Outcomes among Central Canadian Aboriginal. Can J Gastroenterol Hepatol 2016;2016:8987976. doi:10.1155/2016/8987976

32. Cadranel JF, Di Martino V, Lambrey G, et al. Prevalence of hepatitis $\mathrm{C}$ infection and risk factors in hospitalized diabetic patients: results of a cross-sectional study. Eur J Gastroenterol Hepatol 2008;20:829-836. doi:10.1097/MEG.0b013e3282fc73a1 